\title{
TANDEM-X MISSION STATUS
}

\author{
M. Zink
}

DLR, Microwaves and Radar Institute, 82234 Wessling, Germany - manfred.zink@dlr.de

\author{
Commission VI, WG VI/4
}

KEY WORDS: TanDEM-X, bistatic SAR formation, SAR interferometry, global Digital Elevation Model (DEM)

\begin{abstract}
:
TanDEM-X (TerraSAR-X add-on for Digital Elevation Measurements) is an innovative formation flying radar mission that opens a new era in spaceborne radar remote sensing. Its primary objective is the acquisition of a global Digital Elevation Model (DEM) with unprecedented accuracy (12 m horizontal resolution and $2 \mathrm{~m}$ relative height accuracy). This goal is achieved by extending the TerraSAR-X synthetic aperture radar (SAR) mission by a second TerraSAR-X like satellite, TanDEM-X (TDX). Both satellites fly in close orbit formation of a few hundred meters distance, and the resulting large single-pass SAR interferometer features flexible baseline selection enabling the acquisition of highly accurate cross-track interferograms not impacted by temporal decorrelation and atmospheric disturbances. Beyond the global DEM, several secondary mission objectives based on along-track interferometry as well as new bistatic and multistatic SAR techniques have been defined. Since 2010 both satellites have been operated in close formation to map all land surfaces at least twice and difficult terrain even up to four times. While data acquisition for the DEM generation will be concluded by the end of 2014 it is expected to complete the processing of the global DEM in the second half of 2016.
\end{abstract}

\section{MISSION OBJECTIVES}

Digital Elevation Models (DEMs) are of fundamental importance for a wide range of scientific and commercial applications. Within the \pm 60 deg latitude band, data from the Shuttle Radar Topography Mission (SRTM) featuring $12 \mathrm{~m}$ relative height error at $90 \mathrm{~m}$ spatial sampling are currently the primary source of elevation information. Above 60 deg latitude and for Antarctica only lower resolution data are available on a large scale. The primary objective of the TanDEM-X mission is the generation of a worldwide, consistent, up-to-date, and highprecision DEM, according to the specification listed in Table 1. The mission concept is based on the two Synthetic Aperture Radar (SAR) satellites TerraSAR-X and TanDEM-X flying in close formation operating as the first bistatic SAR interferometer in space (Krieger et al., 2007). Beyond the generation of the global TanDEM-X DEM, local DEMs of even higher accuracy levels and applications based on along-track interferometry (ATI) like measurements of ocean currents are important secondary mission objectives.

\begin{tabular}{|c|c|c|}
\hline Parameter & Definition & Requirement \\
\hline $\begin{array}{l}\text { Relative Vertical } \\
\text { Accuracy }\end{array}$ & $\begin{array}{l}90 \% \text { linear point-to-point } \\
\quad \text { error in } 1^{\circ} \times 1^{\circ} \text { cell }\end{array}$ & $\begin{array}{l}2 \mathrm{~m} \text { (slope }<20 \%) \\
4 \mathrm{~m} \text { (slope }>20 \%)\end{array}$ \\
\hline $\begin{array}{l}\text { Absolute Vertical } \\
\text { Accuracy }\end{array}$ & $90 \%$ linear error & $10 \mathrm{~m}$ \\
\hline Spatial Resolution & independent pixels & $12 \mathrm{~m}$ ( $0.4 \mathrm{arc} \mathrm{sec})$ \\
\hline
\end{tabular}

Table 1. Specification of the Global TanDEM-X DEM.

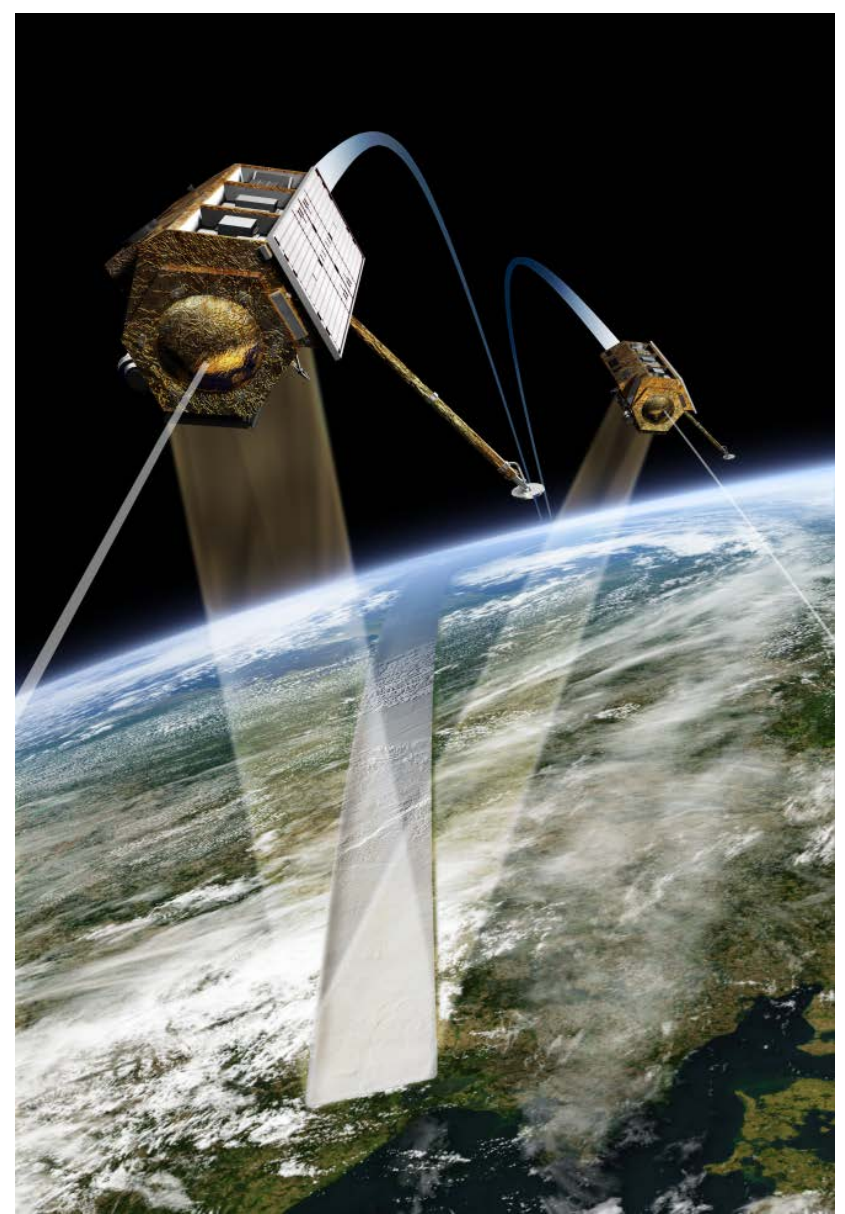

Figure 1. Artist's view of TerraSAR-X and TanDEM-X flying in close formation. 
TanDEM-X has a tight time schedule to achieve the main mission goal. The first four years are dedicated to the global DEM acquisitions using baseline geometries optimized for the DEM performance. A limited number of scientific acquisitions have already been included during periods with suitable baselines. After completing the acquisitions for the global DEM even larger baselines can be adjusted in a dedicated science phase. This enables higher accuracy DEMs on local scales and the demonstration of new scientific applications.

\section{MISSION CONCEPT}

The TanDEM-X mission is an extension of the TerraSAR-X radar mission (Werninghaus et al., 2010), co-flying a second satellite of nearly identical capability in a close formation. The TerraSAR-X satellite (TSX), as basis for TanDEM-X, was successfully launched on June 15, 2007. The nominal orbit height is $514.8 \mathrm{~km}$ and the orbit repeat cycle is 11 days. TSX is not only a high performance SAR system, but it has already built in all necessary features required for the implementation of the TanDEM-X mission. Examples are additional X-band horn antennas for inter-satellite phase synchronization, the availability of a dual-frequency GPS receiver for precise orbit determination, excellent RF phase stability of the SAR instrument, and PRF synchronization based on GPS as a common time reference. The second satellite (TDX, launched June 21, 2010) is a close copy of TSX with only minor modifications like an additional cold gas propulsion system for formation fine tuning, double-sized on-board solid-state memory for increased data recording capacity, and an additional S-band receiver to enable the reception of telemetry and GPS position information broadcast by TSX. The instruments on both satellites are advanced high-resolution X-band synthetic aperture radars, which can be operated in Spotlight, Stripmap, and ScanSAR mode with full polarization capability (Pitz et al., 2010). The TSX and TDX satellites were designed for a nominal lifetime of 5.5 years. Predictions for TSX based on the current status of system resources indicate up to six extra years (until the end of 2018) of lifetime, providing at least eight years of joint operation with TDX.

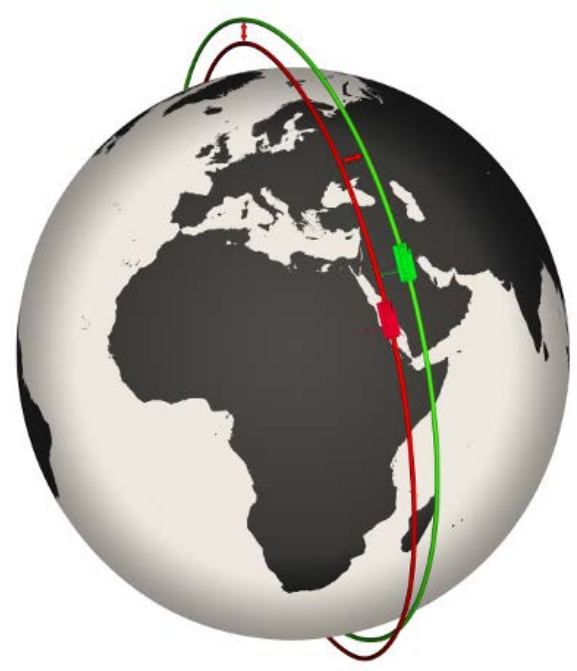

Figure 2. Orbit illustration of Helix formation. Red: TSX, Green: TDX; typical baseline values vary from 120 to $500 \mathrm{~m}$.

\subsection{Close Formation Flight}

An orbit configuration based on a helix geometry has been selected for safe formation flying. The helix-like relative movement of the satellites along the orbit is achieved by combination of an out-of-plane (horizontal) orbital displacement imposed by different ascending nodes with a radial (vertical) separation imposed by the combination of different eccentricities and arguments of perigee. Since the satellite orbits never cross, the satellites can be arbitrarily shifted along their orbits. This enables a safe spacecraft operation without the necessity for autonomous control. Cross- and along-track baselines ranging from $120 \mathrm{~m}$ to $10 \mathrm{~km}$ and from 0 to several $100 \mathrm{~km}$, respectively, can be accurately adjusted depending on the measurement requirements.

For a complete mapping of the Earth with dedicated heights of ambiguity the Helix formation parameters, namely the horizontal and the vertical distance between the satellites and the so-called phase of libration (Krieger et al, 2007), are constantly adjusted. The term "motion of libration" denotes the natural rotation of the eccentricity vectors due to secular disturbances. The phases of this libration can either be kept in a fixed relative position with small maneuvers using the cold gas thrusters on a daily basis, or let drift for fine tuning of the crosstrack baselines. Southern and northern latitudes can be mapped with the same formation by using ascending orbits for one and descending orbits for the other hemisphere.

\subsection{Interferometric Acquisition Modes}

TanDEM-X can acquire interferometric data in different configurations (Krieger et al., 2007): examples are the bistatic, monostatic, and alternating bistatic modes. The different interferometric configurations can be further combined with different TSX and TDX SAR imaging modes like Stripmap, ScanSAR, and Sliding Spotlight. Operational DEM generation is performed using the bistatic Stripmap mode in single horizontal polarization. This mode uses either TSX or TDX as a transmitter to illuminate a common radar footprint on the Earth's surface. The scattered signal is then recorded by both satellites simultaneously. This simultaneous data acquisition makes dual use of the available transmit power and is mandatory to avoid possible errors from temporal decorrelation and atmospheric disturbances.

\subsection{System Synchronisation}

A peculiarity of the bistatic data acquisition is the use of independent oscillators for the modulation and demodulation of the radar pulses. Any deviation between the two oscillators will hence cause a residual modulation of the recorded azimuth signal. The impact of oscillator phase noise in bistatic SAR has been investigated in (Krieger et al., 2006), where it is shown that oscillator noise may cause significant errors in both the interferometric phase and SAR focusing.

The stringent requirements for interferometric phase stability in the bistatic mode will hence require an appropriate relative phase referencing between the two SAR instruments or an operation in the alternating bistatic mode. For TanDEM-X, a dedicated inter-satellite X-band synchronisation link has been established: the nominal bistatic SAR data acquisition is shortly interrupted, and radar pulses are exchanged between the two satellites using dedicated synchronization horn antennas. On 
ground, a correction signal can be derived from the recorded synchronization pulses, which compensates the oscillatorinduced phase errors in the bistatic SAR signal. The performance of such a synchronization link has been investigated in (Younis et al., 2006) indicating that a phase error below $1^{\circ}$ can be achieved, which has been validated during the bistatic TanDEM-X commissioning phase (Rizzoli et al, 2011).

\subsection{Performance Prediction and Global Acquisition Plan}

Radar interferometry is based on the evaluation of the phase difference between two coherent radar signals acquired from slightly different spatial and/or temporal positions. By this, TanDEM-X is able to measure the range difference $\Delta r$ between the two satellites and a given scatterer on the ground at millimeter accuracy. The height of the scatterer is inferred from this range difference by geometric triangulation. The sensitivity of the phase-to-height scaling depends on the distance between the two satellites, where a larger perpendicular baseline $B_{\perp}$ increases the sensitivity of the radar interferometer to small height variations. However, the conversion from phase to range and hence the conversion of phase differences to height is not unique, since the range difference measurement via phases is ambiguous with the wavelength. Radar interferometry expresses this ambiguity by the so-called height of ambiguity:

$$
h_{a m b}=\frac{\lambda r_{0} \sin \left(\theta_{i}\right)}{B_{\perp}}
$$

where $\lambda$ is the wavelength, $r_{0}$ is the slant range from the satellites to the scatterer under consideration, and $\theta_{i}$ is the local incident angle of the electromagnetic wave.

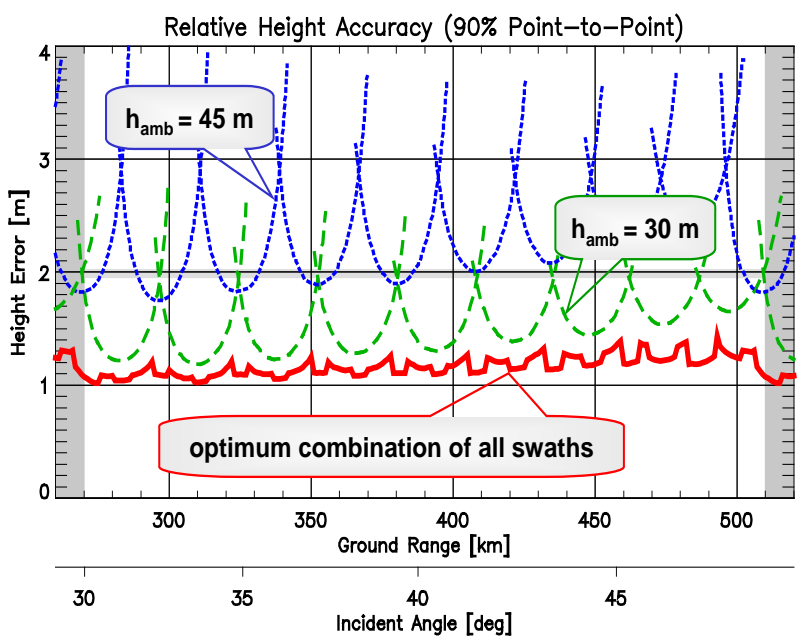

Figure 3. Predicted relative height accuracy for a height of ambiguity of $45 \mathrm{~m}$ (dotted) and $30 \mathrm{~m}$ (dashed). The lower solid curve shows the error resulting from the combination.

Figure 3 shows the predicted relative height accuracy as a function of ground range position and the height of ambiguity (cf. (Krieger et al., 2007) for details). This prediction has been validated by systematic height accuracy evaluations of repeatedly acquired TanDEM-X DEMs (Rizzoli et al., 2012). Figure 3 makes clear that a lower height of ambiguity (i.e. a larger baseline) improves the height accuracy. However, a lower height of ambiguity also increases the difficulties in phase unwrapping. To overcome these problems and to ensure a homogeneous performance, TanDEM-X combines acquisitions with different heights of ambiguity, as shown in Figure 3. In addition, the swath positions for the second global coverage are shifted w.r.t. the first coverage such that the combination of the two "clapboard" patterns in Figure 3 results in a homogeneous height error across the complete incidence angle range. Moreover, difficult areas like mountainous regions are acquired a third and a fourth time using a different viewing geometry in order to mitigate shadow and layover effects (Borla Tridon et al., 2013). Sandy deserts strongly affect the SAR performance because of the weak power of the backscattered signal from sand. These critical areas are reacquired using steep incidence angles in order to further improve the interferometric performance (Martone et al., 2014).

A homogeneous height performance is the key driver in the planning of the global DEM acquisitions. It requires frequent adjustments of the Helix formation parameters taking into account constraints on the available amount of fuel and thruster cycles, limitations in the on-board storage and downlink capacity, as well as power and thermal restrictions. The result of this optimization process is a globally oriented acquisition scenario (Borla Tridon et al., 2013).

\section{CALIBRATION OF THE BISTATIC INTERFEROMETER}

Data for the global DEM are collected in Stripmap mode at swath widths of $30 \mathrm{~km}$. In a fully automated first processing step, the data are divided into individual scenes, so-called Raw DEMs, with an extent of $30 \mathrm{~km}$ x $50 \mathrm{~km}$. Each Raw DEM already needs to be as close as possible to its real height to allow an accurate geocoding and to facilitate the second processing step, in which blocks of the different scenes are calibrated against their neighbours and against ICESat reference heights. This is done in order to further improve the absolute height accuracy and to allow a seamless mosaicking of adjacent scenes without tilts or displacements.

Interferometric calibration aims at delivering precise and well geocoded Raw DEMs. It includes the calibration of the baseline between both satellites (Hueso Gonzalez et al., 2012) at millimeter accuracy and the precise determination of differential internal delays (Walter Antony et al, 2013) to allow a radargrammetric determination of the coarse absolute height of the Raw DEM.

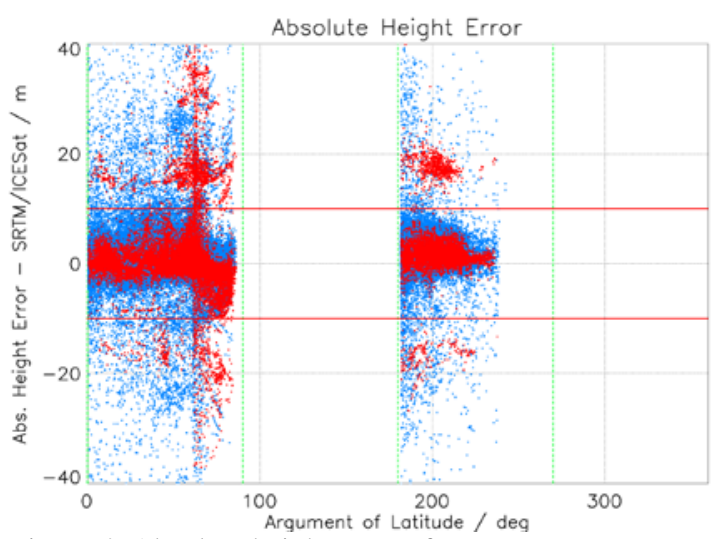

Figure 4. Absolute height error of TanDEM-X Raw DEMs compared to SRTM/ICESat for first (blue) and second (red) coverage. 


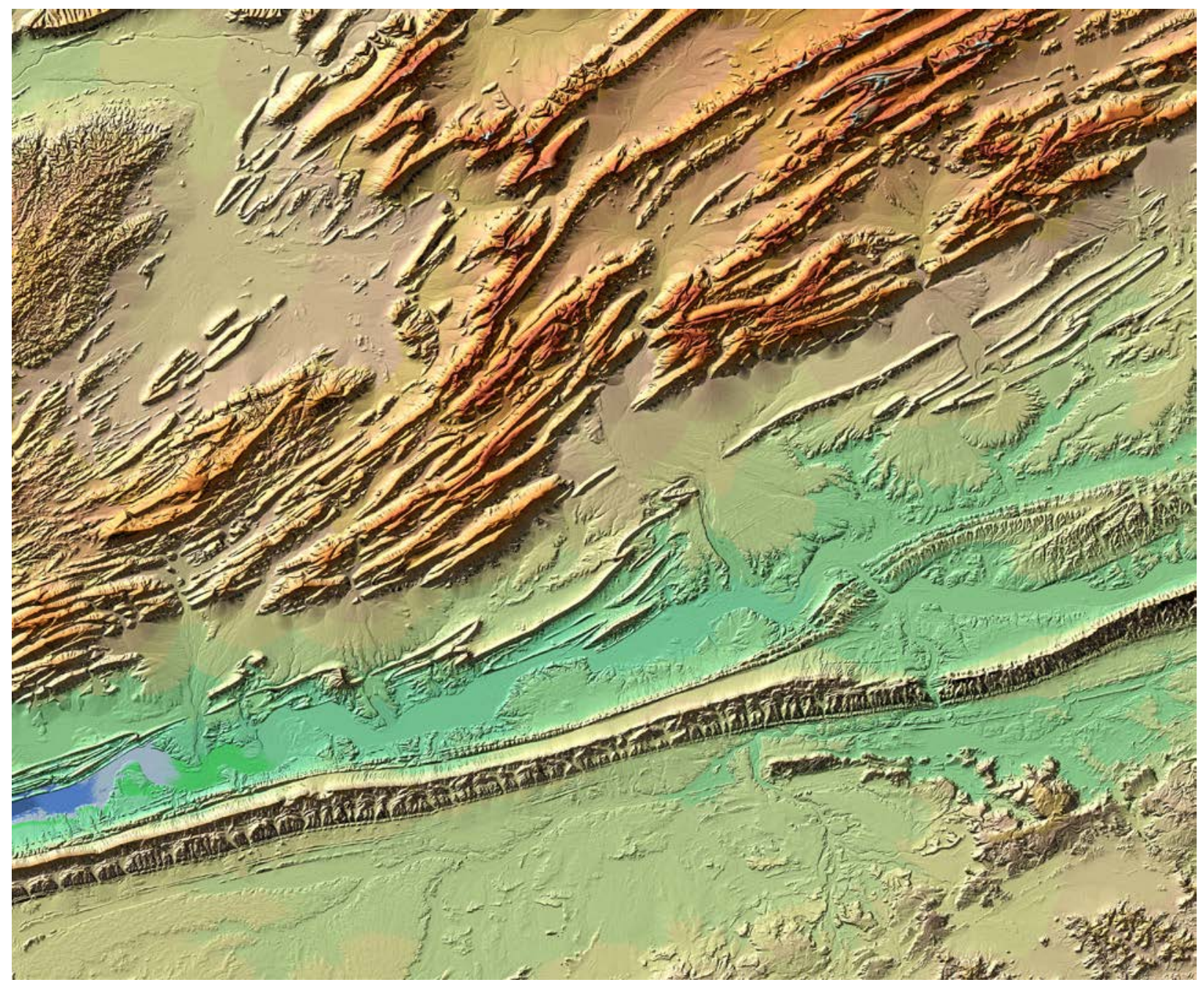

Figure 5. Final TanDEM-X DEM over Guelmim Es Semara, Marocco.

The final adjustment is performed by calibrating the phase offset between both acquisitions based on a comparison with reference data (SRTM and ICESat). ${ }^{1}$ This phase offset depends on the transmitting satellite, on precise synchronization and start-stop time determination, and on the inclusion of tropospheric path delays (Bachmann et al., 2012), (Krieger et al., 2012). It has been adjusted such that $90 \%$ of all Raw DEMs initially are within \pm 10 m versus SRTM/ICESat, as can be seen in Figure 4 . The residual $10 \%$ are mainly caused by an unresolvable ambiguity in the synchronization link (the socalled $\pi$-ambiguity). These ambiguities are largely corrected by reprocessing with a measured phase cycle offset as input which is compensated for in the phase-to-height conversion.

\section{DEM PROCESSING CHAIN}

The processing from instrument raw data to the final DEM products is performed by two consequent processors: the Integrated TanDEM-X Processor (ITP) (Fritz et al., 2012) and the Mosaicking and Calibration Processor (MCP) (Wessel et al., 2008).

\footnotetext{
${ }^{1}$ SRTM is used for absolute height comparison in the latitude regions between $+/-60^{\circ}$. ICESat points are used for regions outside the SRTM coverage.
}

\subsection{The Integrated TanDEM-X Processor (ITP)}

The ITP is a systematic and mainly data driven automatic chain which comprises SAR and interferometric processing. It ingests and screens the incoming acquisitions, focuses the individual scenes in parallel to resampled complex images, calculates the filtered interferogram, performs the phase unwrapping and height pre-calibration for accurate phase-to-height conversion and finally generates the geocoded Raw DEMs. The whole processing does not require any external height references, even the determination of the phase ambiguity band is based on radargrammetry using only TanDEM-X data. The Raw DEMs are archived along with the associated height error maps, the amplitudes, flag masks, additional quality control and system calibration data, and submitted to the operator driven MCP. The complex SAR data sets are archived as well as the so-called Coregistered Single-look Slant-range Complex (CoSSC) products which are used as supporting data for multi-baseline phaseunwrapping and for dedicated re-processing scenarios.

\subsection{The Mosaicking and Calibration Processor (MCP)}

After Raw DEM generation the last two steps for the production of TanDEM-X DEM products are the calibration of DEM acquisitions to reference heights and the mosaicking of single interferometric Raw DEMs into geocells. DEM calibration 
requires a global set of suitable height references. For TanDEM$\mathrm{X}$ the ICESat data are used as ground control points. The ICESat spaceborne laser altimeter provides height references with a standard deviation below $2 \mathrm{~m}$ at a sampling distance of $170 \mathrm{~m}$ in along-track and a maximum across track distance of $80 \mathrm{~km}$ at the equator. A small subset of selected ICESat points is used for calibration, and the remaining majority is used for validation of the final DEM heights. Furthermore, tie points in the more than $3 \mathrm{~km}$ wide overlap between neighboring DEM swaths are used to ensure the relative height calibration. For each data take, estimates of the height offset, tilt in range, and slope in the azimuth direction is being derived by means of a weighted least-squares adjustment (Gruber et al., 2012). In the mosaicking, the calibration corrections are applied to each DEM and different coverages are mosaicked by a weighted average of all elevation values at a given position.

\section{MISSION STATUS SUMMARY}

After the TanDEM-X launch in June 2010 the monostatic commissioning phase was dedicated to calibration and performance verification and revealed calibration accuracies and overall performance of the TDX SAR system and its products as good as for TSX. After comprehensive testing of the various safety measures, close formation was achieved mid October 2010 and the operation at typical distances between $120 \mathrm{~m}$ and $500 \mathrm{~m}$ is running remarkably smooth and stable since then.

The subsequent bistatic commissioning phase of the TanDEM$\mathrm{X}$ mission concentrated on checking out the complete bistatic chains, from acquisition planning to bistatic and interferometric processing and generation of so-called Raw DEMs. Global DEM acquisitions have started in December 2010 and the first and second global coverage (except Antarctica) was completed in March 2012 and March 2013, respectively. After an acquisition period for gap filling, Antarctica was mapped during local winter conditions (in order to achieve a better signal-tonoise ratio) and since early August 2013 the Helix formation has been re-adjusted to allow imaging of difficult mountainous terrain from the opposite viewing geometry (Borla Tridon et al., 2013). After reversing the Helix formation in April 2014, a subsequent second coverage of Antarctica, and some further gap filling, data acquisitions for the global DEM was finalized in early 2015 (Borla Tridon et al., 2014).

Parallel to the first months of operational data acquisition the team concentrated its efforts on the calibration of the bistatic interferometer. Correction of differential delays between TSX and TDX was necessary to facilitate the utilization of radargrammetry for resolving the ambiguity band. Phase, delay, and baseline calibration have reached such an accuracy level, that more than $90 \%$ of all so-called Raw DEMs are within $\pm 10 \mathrm{~m}$ of the DEM derived from SRTM/ICESat data already before the final calibration step using ICESat data as reference heights.

A comprehensive system has been established for continuous performance monitoring and verification (Martone et al., 2012) (Bräutigam et al., 2012) including feedback to the TanDEM-X acquisition planning for additional acquisitions. Up to now, more than 550,000 Raw DEMs have been generated in a fully automated process employing multibaseline interferometric techniques (Fritz et al., 2012), (Lachaise et al., 2012).

The final calibration and mosaicking chain is fully operational since 2013. Based on the first global acquisition, so-called Intermediate DEMs (IDEMs) have been produced for larger regions. Currently, all efforts are concentrated on the generation of final DEM products. Since mid-March 2015 final TanDEM$X$ DEMs are available for more than $50 \%$ of the global landmass. This includes the complete Australia, more flat areas

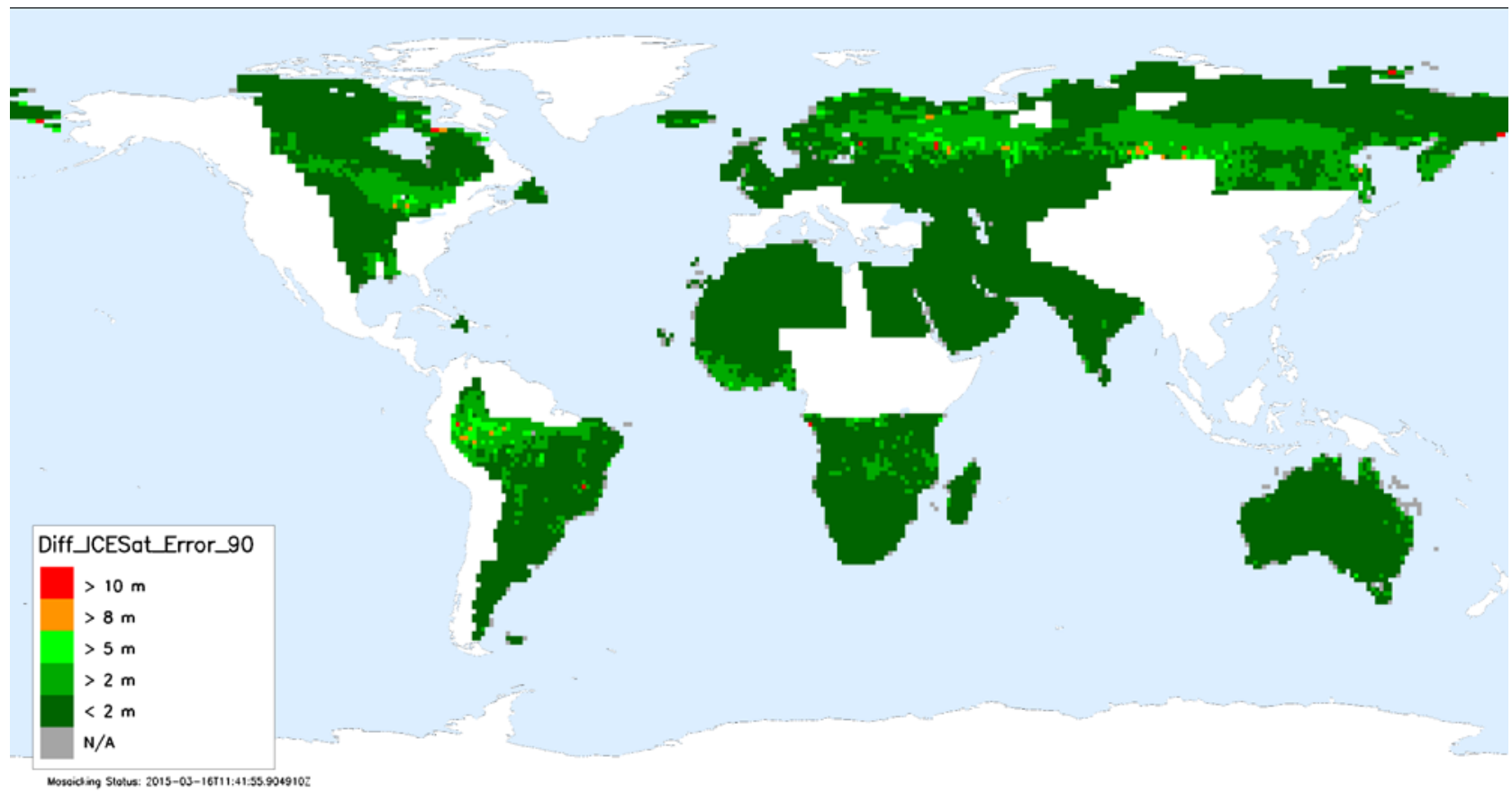

Figure 6. Global map showing 90\% absolute height accuracy per final DEM tile in meter (status February 2015). 
in North- and South America, Russia, Africa and Europe. First mountainous areas in the north-east of Russia and in the far and middle East are available as well. The quality so far is well within specifications. In Figure 6 the absolute height error $(90 \%$ confidence level) is depicted for the available final DEM products. The absolute height accuracy measured at global scale is of about $1.2 \mathrm{~m}$, which verifies the outstanding quality of the TanDEM-X DEM (see Table 1) (Bräutigam et al., 2015). Examples of final TanDEM-X DEMs are depicted in Figure 5, 7, and 8. It is expected to complete the global DEM in the second half of 2016. In total more than 19,000 TanDEM-X DEM tiles will be generated. Note here that in the higher latitudes one TanDEM-X tile covers up to four $1^{\circ} \times 1^{\circ}$ geocells.

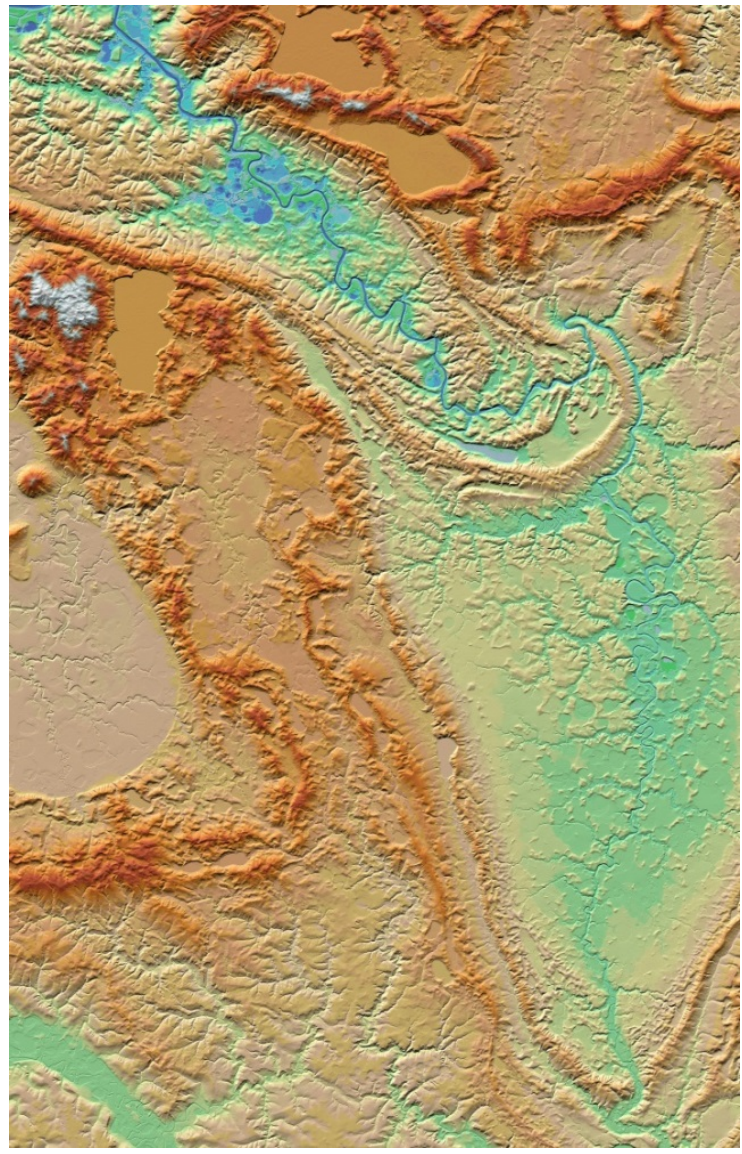

Figure 7. Final TanDEM-X DEM over North-Sibirian low lands.

\section{TANDEM-X SCIENCE PHASE}

TanDEM-X provides the remote sensing scientific community not only with a global DEM of unprecedented accuracy, but also with a unique reconfigurable SAR system to demonstrate novel bistatic and multistatic radar techniques for enhanced bioand geophysical parameter retrieval. Several bistatic experiments were already conducted during the TanDEM-X commissioning phase (Krieger et al., 2014), (Rodriguez-Cassola et al., 2012), (Lopez-Dekker et al., 2011). To foster the development of further innovative bistatic and multistatic SAR techniques (Cloude et al., 1998), TanDEM-X is operated in a dedicated science phase from October 2014 until December 2015 (Hajnsek, 2015).

\section{CONCLUSION}

The TanDEM-X mission opens a new era in spaceborne radar remote sensing. A large single-pass SAR interferometer with adjustable baselines has been formed by adding a second, almost identical radar satellite to TerraSAR-X and flying both satellites in a closely controlled formation. This enables not only the acquisition of a global DEM with unprecedented accuracy, but also the demonstration of highly innovative bistatic and multistatic SAR techniques and applications. These experiments form the basis for future formation flying SAR missions (D’Errico, 2013), (Krieger et al., 2010).

Key technologies like close formation flying, bistatic SAR operation and synchronization, precise baseline estimation and calibration as well as sophisticated bistatic and interferometric processing chains have been implemented. Appropriate safety mechanisms enable safe operation at typical satellite distances between $120 \mathrm{~m}$ and $500 \mathrm{~m}$. The complete mission is fully operational since December 2010 and both satellites as well as the ground system perform remarkably well. Data acquisition for the global DEM was finished in early 2015. The current focus is on the processing of the global DEM data. More than $50 \%$ of the global land mass covering Australia, more flat areas in North- and South America, Russia, Africa and Europe as well as first mountainous areas in the north-east of Russia and in the far and middle East are already available as final DEM products. The global DEM will be available by the end of 2016, and is expected to become a new reference for commercial (http://www.astrium-geo.com/en/168-tandem-X-global-dem) and scientific applications (www.dlr.de/HR/tandem-x) since its $3 \mathrm{D}$ information content is at least 30 times more accurate than the presently available global scale DEM data set.

Since the completion of the DEM data acquisition various scientific radar experiments are conducted in a dedicated Science Phase (from October 2014 until the end of 2015) to demonstrate the great potential of future formation flying interferometric SAR missions to serve novel remote sensing applications.

\section{ACKNOWLEDGEMENTS}

I acknowledge the great effort and enthusiasm of the teams at DLR and AIRBUS Defence \& Space who made this ambitious mission a reality. The TOR instruments are an in kind contribution by the Helmholtz Centre Potsdam (GFZ), who is also performing precise baseline determination. TanDEM-X is partly funded by the German Federal Ministry for Economic Affairs and Energy (50 EE 1035) and realized in a publicprivate partnership between DLR and AIRBUS Defence \& Space.

\section{REFERENCES}

Bachmann, M., Hueso Gonzalez, J., Krieger, G., Schwerdt, M., Walter Antony, J., De Zan, F., 2012. Calibration of the Bistatic TanDEM-X Interferometer. European Conference on Synthetic Aperture Radar (EUSAR), Nuremberg, Germany.

Borla Tridon, D., Bachmann, M., Schulze, D., Ortega Miguez, C. J., Polimeni, M. D., Martone, M., Böer, J., Zink, M., 2013. TanDEM-X: DEM Acquisition in the Third Year Era. Int. Journal of Space Science and Engineering, 1(4) pp. 367 - 381. 


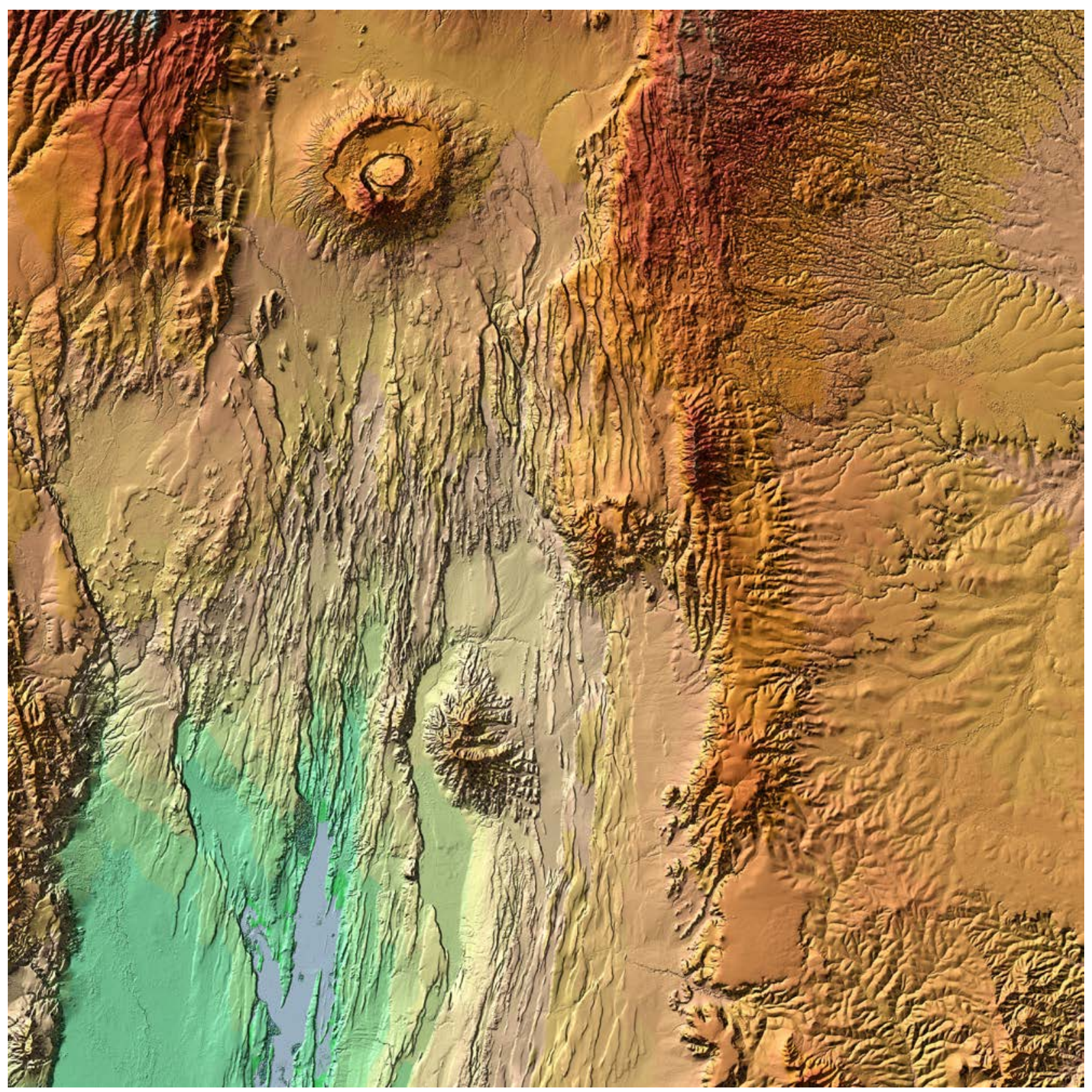

Figure 8. Final TanDEM-X DEM tile around Mount Suswa Conservancy, Kenya.

Borla Tridon, D., Bachmann, M., Schulze, D., Polimeni, M. D., Martone, M., Böer, J., Zink, M., 2014. TanDEM-X DEM Difficult Terrain \& Antarctica Acquisitions towards the Planning of the Science Phase. $10^{\text {th }}$ European Conference on Synthetic Aperture Radar (EUSAR), Berlin, Germany.

Bräutigam, B., Rizzoli, P., Martone, M., Bachmann, M., Kraus, T., Krieger, G., 2012. InSAR and DEM Quality Monitoring of TanDEM-X. International Geoscience and Remote Sensing Symposium (IGARSS), Munich, Germany.

Bräutigam B. et al. 2015. Quality Assessment for the first Part of the TanDEM-X Global Digital Elevation Model. 36th International Symposium on Remote Sensing of Environment (ISRSE), Berlin, Germany.
Cloude, S. and Papathanassiou, K., 1998. Polarimetric SAR Interferometry. IEEE Transactions on Geoscience and Remote Sensing, 36, pp. 1551-1565.

D’Errico, M., 2013. Distributed Space Missions for Earth System Monitoring. Springer, New York.

Fritz, T., Breit, H., Rossi, C., Balss, U., Lachaise, M., Duque, U., 2012. Interferometric Processing and Products of the TanDEM-X Mission. International Geoscience and Remote Sensing Symposium (IGARSS), Munich, Germany.

Gruber, A., Wessel, B., Huber, M., Roth, A., 2012. Operational TanDEM-X DEM Calibration and First Validation Results. ISPRS Journal of Photogrammetry and Remote Sensing, 38, pp. 39-49. 
Hajnsek, I., 2015. TanDEM-X: Science Activities. 36th International Symposium on Remote Sensing of Environment (ISRSE), Berlin, Germany.

Hueso González, J., Walter Antony, J., Bachmann, M., Krieger, G., Zink, M., Schrank, D., Schwerdt, M., 2012. Bistatic System and Baseline Calibration in TanDEM-X to Ensure the Global Digital Elevation Model Quality. ISPRS Journal of Photogrammetry and Remote Sensing, 38, pp. 3-11.

Krieger, G. and Younis, M., 2006. Impact of Oscillator Noise in Bistatic and Multistatic SAR. IEEE Geoscience and Remote Sensing Letters, 3, pp. 424- 428 .

Krieger, G., Moreira, A., Fiedler, H., Hajnsek, I., Werner, M., Younis, M., Zink, M., 2007. TanDEM-X: A Satellite Formation for High Resolution SAR Interferometry. IEEE Transactions on Geoscience and Remote Sensing, 45(11), pp. 3317-3341.

Krieger, G., Hajnsek, I., Papathanassiou, K., Younis, M., Moreira, A., 2010. Interferometric Synthetic Aperture Radar (SAR) Missions Employing Formation Flying. Proceedings of the IEEE, 58(5), pp. 816843.

Krieger, G. and De Zan, F., 2012. Relativistic Effects in Bistatic SAR Processing and System Synchronization. European Conference on Synthetic Aperture Radar (EUSAR), Nuremberg, Germany.

Krieger, G., Zink, M., Bachmann, M., Bräutigam, B., Schulze, D., Martone, M., Rizzoli, P., Steinbrecher, U., Walter Antony, J., De Zan, F., Hajnsek, I., Papathanassiou, K., Kugler, F., Rodriguez Cassola, M., Younis, M., Baumgartner, S., López-Dekker, F., Prats, P., Moreira, A., 2014. TanDEM-X: A Radar Interferometer with Two Formation-Flying Satellites. Acta Astronautica, 89, pp. 83-98.

Lachaise, M., Balss, U., Fritz, T., Breit, H., 2012. The Dual-Baseline Interferometric Processing Chain for the TanDEM-X Mission. International Geoscience and Remote Sensing Symposium (IGARSS), Munich, Germany.

Lopez-Dekker, F., Prats, P., De Zan, F., Schulze, D., Krieger, G., Moreira, A., 2011. TanDEM-X First DEM Acquisition: A Crossing Orbit Experiment. IEEE Geoscience and Remote Sensing Letters, 8(5), pp. 943-947.
Martone, M., Bräutigam, B., Rizzoli, P., Gonzalez, C., Bachmann, M., Krieger, G., 2012. Coherence Evaluation of TanDEM-X Interferometric Data. ISPRS Journal of Photogrammetry and Remote Sensing, 38, pp. 21-29.

Martone, M., Bräutigam, B., Rizzoli, P., Krieger, G., 2014. TanDEM-X performance over sandy areas, in Proc. EUSAR, Berlin, Germany. Pitz, W. and Miller, D., 2010. The TerraSAR-X Satellite. IEEE Transactions on Geoscience and Remote Sensing, 48(2), pp. 615-622.

Rizzoli, P. et al., 2011. Interferometric Performance. presentation at TanDEM-X science meeting, Oberpfaffenhofen, Germany, available online at

http://www.dlr.de/Portaldata/32/Resources/dokumente/tdmx/sciencemee ting3/08-Interferometric_Performance_Handout_small.pdf

Rizzoli, P., Bräutigam, B., Kraus, T., Martone, M., Krieger, G., 2012. Relative Height Error Analysis of TanDEM-X Elevation Data. ISPRS Journal of Photogrammetry and Remote Sensing, 73, pp. 30-38.

Rodriguez Cassola, M., Prats, P., Schulze, D., Tous-Ramon, N., Steinbrecher, U., Marotti, L., Nannini, M., Younis, M., Lopez-Dekker, F., Zink, M., Reigber, A., Krieger, G. and Moreira, A., 2012. First Bistatic Spaceborne SAR Experiments with TanDEM-X. IEEE Geoscience and Remote Sensing Letters, 9(1), pp. 33-37.

Walter Antony, J., Hueso González, J., Schwerdt, M., Bachmann, M., Krieger, G., Zink, M., 2013. Results of the TanDEM-X Baseline Calibration. IEEE Journal of Selected Topics in Applied Earth Observations and Remote Sensing, 6(3), pp. 1495-1501.

Werninghaus, R. and Buckreuss, S., 2010. The TerraSAR-X Mission and System Design. IEEE Transactions on Geoscience and Remote Sensing, 48(2), pp. 606-614.

Wessel, B., Marschalk, U., Gruber, A., Huber, M., Hahmann, T., Roth, A., Habermeyer, M., 2008. Design of the DEM Mosaicking and Calibration Processor for TanDEM-X. European Conference on Synthetic Aperture Radar (EUSAR), Friedrichshafen, Germany.

Younis, M., Metzig, R., Krieger, G., 2006. Performance Prediction of a Phase Synchronization Link for Bistatic SAR. IEEE Geoscience and Remote Sensing Letters, 3, pp. 429- 433. 